Article

\title{
HIV Replication in Humanized IL-3/GM-CSF-Transgenic NOG Mice
}

\author{
Federico Perdomo-Celis ${ }^{1,2}{ }^{\oplus}$, Sandra Medina-Moreno ${ }^{1}$, Harry Davis ${ }^{1}$, Joseph Bryant ${ }^{1}$ and \\ Juan C. Zapata ${ }^{1, *(D)}$ \\ 1 Institute of Human Virology, School of Medicine, University of Maryland, Baltimore, MD 21201, USA; \\ fcelis@ihv.umaryland.edu or federico.perdomo@usco.edu.co (F.P.-C.); \\ smmoreno@ihv.umaryland.edu (S.M.-M.); hdavis@ihv.umaryland.edu (H.D.); \\ jbryant@ihv.umaryland.edu (J.B.) \\ 2 Grupo Inmunovirología, Facultad de Medicina, Universidad de Antioquia, UdeA, Medellín 050010, \\ Colombia \\ * Correspondence: jczapata@ihv.umaryland.edu; Tel.: +1-410-706-4611
}

Received: 25 January 2019; Accepted: 6 March 2019; Published: 12 March 2019

\begin{abstract}
The development of mouse models that mimic the kinetics of Human Immunodeficiency Virus (HIV) infection is critical for the understanding of the pathogenesis of disease and for the design of novel therapeutic strategies. Here, we describe the dynamics of HIV infection in humanized NOD/Shi-scid-IL2r $\gamma^{\text {null }}$ (NOG) mice bearing the human genes for interleukin (IL)-3 and granulocyte-macrophage colony-stimulating factor (GM-CSF) (NOG-EXL mice). The kinetics of viral load, as well as the frequencies of T-cells, B-cells, Natural killer cells (NK), monocytes, and dendritic cells in blood and secondary lymphoid organs were evaluated throughout the time of infection. In comparison with a non-transgenic humanized mouse (NSG) strain, lymphoid and myeloid populations were more efficiently engrafted in humanized NOG-EXL mice, both in peripheral blood and lymphoid tissues. In addition, HIV actively replicated in humanized NOG-EXL mice, and infection induced a decrease in the percentage of $\mathrm{CD} 4^{+} \mathrm{T}$-cells, inversion of the $\mathrm{CD} 4: \mathrm{CD} 8$ ratio, and changes in some cell populations, such as monocytes and dendritic cells, that recapitulated those found in human natural infection. Thus, the humanized IL-3/GM-CSF-transgenic NOG mouse model is suitable for the study of the dynamics of HIV infection and provides a tool for basic and preclinical studies.
\end{abstract}

Keywords: NOG mice; Humanized mice (huNOG or huNOG-EXL); GM-CSF; IL-3; HIV

\section{Introduction}

An important limitation for the study of Human Immunodeficiency Virus (HIV) infection pathogenesis is the species-specificity of this virus [1]. Although models of Simian Immunodeficiency Virus (SIV) infection in nonhuman primates have largely contributed to a better knowledge of HIV pathophysiology, disadvantages of their use include the high cost and increased gestation period, limitation to a smaller number of animals, host restriction factors that affect viral replication, and ethical concerns, among other considerations [2,3]. Although mice cannot support HIV infection, mouse humanization via transplantation of $\mathrm{CD} 34^{+}$hematopoietic stem cells (HSCs) into immunodeficient strains offers the possibility to study different human diseases after reconstitution of cell populations [4]. In addition, immunodeficient mouse models allow the creation of knock-out or transgenic strains for the study of specific host features and their impact on disease dynamics. For instance, transgenic mice expressing the human cytokines, interleukin (IL)-3 and granulocyte-macrophage colony-stimulating factor (GM-CSF), support the heightened engraftment of myeloid cells [5], which could be useful for the study of the role of these subsets in the pathogenesis or resistance to HIV infection. 
Here, we describe the kinetics of T-cells, B-cells, natural killer (NK) cells, monocytes, and myeloid and plasmacytoid dendritic cells (mDCs and pDCs) in humanized NOD/Shi-scid-IL2r $\gamma^{\text {null }}$ (NOG) mice [6] transgenic for the human IL-3 and GM-CSF (huNOG-EXL mice) [7], in basal conditions and during HIV infection. Our results indicate that this model recapitulates some features of HIV infection, such as the increase in the viral load, inversion of the CD4:CD8 ratio, and changes in some lymphoid and myeloid populations in peripheral blood and lymphoid tissues, and support its usefulness for basic and preclinical studies.

\section{Results and Discussion}

\subsection{Characterizing Lymphoid and Myeloid Populations in huNOG-EXL Mice}

Through flow cytometry and the use of anti-human monoclonal antibodies, here, we evaluated the engraftment of human lymphoid and myeloid cell populations in huNOG-EXL. We first characterized cell populations in huNOG-EXL mice in basal conditions and compared them with huNSG control mice, after 10-14 weeks post-engraftment. Of note, NSG mice bear a genetic background similar to NOG mice [8], but they exhibit full absence of IL2r $\gamma$, in contrast to NOG mice, which contain a non-functional truncated IL2r $\gamma$. NSG mice are not transgenic for human IL-3 and GM-CSF [9]. NOG-EXL mice are commercially available from Taconic, and NSG mice were used according to our in-house-standardized conditions $[10,11]$. NSG mice are a reference strain and are widely used for HIV studies [12-14].

T-cells, B-cells, NK cells (CD56 bright $^{\text {CD56 }}{ }^{\mathrm{dim}}$, and CD56-) [15], monocytes (classical, intermediate, and non-classical) [16], and $\mathrm{mDCs}$ and $\mathrm{pDCs}[17,18]$ were identified according to the gating strategy shown in Figure 1. In the case of T-cells, we also explored CXCR5-expressing cells as an indirect measurement of the development of lymphoid follicles and cell homing to these structures in secondary lymphoid organs (SLO) $[19,20]$. As shown in Figure 2, compared with huNSG mice, huNOG-EXL mice had higher levels of engraftment, evaluated by the percentage of human $\mathrm{CD} 45^{+}$ cells in blood (Figure 2A). huNOG-EXL exhibited lower frequencies of circulating T-cells than huNSG mice, at expenses of higher proportions of B-cells (Figure 2B,C). There were no differences in the CD4:CD8 ratios between both mice strains (Figure 2D). Finally, huNOG-EXL had higher frequencies of circulating CXCR5 ${ }^{+} \mathrm{CD}^{+}$(Figure 2E) and $\mathrm{CD} 8^{+}$T-cells (Figure 2F). On the other hand, huNOG-EXL and huNSG mice had comparable frequencies of CD45 $5^{+}$cells, T-cells, and B-cells in SLO (spleen, axillary [ALN], and mesenteric lymph nodes [MLN]) (Figure 2A-C), but huNOG-EXL exhibited higher proportions of $\mathrm{CXCR}^{+} \mathrm{CD}^{+} \mathrm{T}$-cells (Figure $2 \mathrm{E}$ ).

NK cells were evaluated from FSC-A ${ }^{\text {lo }} \mathrm{CD}^{-}$cells. Similar to previous human reports [21,22], in huNOG-EXL mice, CD56 ${ }^{\mathrm{dim}}$ cells constituted the major NK cell subset (Figure 1), with a median (range) of $90.7 \%(89.6 \%-96.7 \%)$ among the total NK cells. However, most of CD56 ${ }^{\mathrm{dim}}$ NK cells were $\mathrm{CD}^{-} 6^{-}$(Figure 1), contrary to human reports [23], and consistent with a less mature state [24]. CD56 ${ }^{-}$ and CD56 bright $\mathrm{NK}$ cells had a median (range) of $8.5 \%(3.3 \%-10 \%)$ and $0.2 \%(0 \%-1.7 \%)$ among total NK cells, respectively. As shown in Figure 3, compared with huNSG mice, huNOG-EXL mice had higher frequencies of circulating CD56 ${ }^{\mathrm{dim}}$ and $\mathrm{CD} 56^{-} \mathrm{NK}$ cells, with comparable frequencies of CD56 bright NK cells in blood between both mice strains. Notably, NK cell subsets were barely detectable in SLO (Figure 3). Particularly in the case of CD56 ${ }^{\text {bright }}$ and $\mathrm{CD} 56^{-}$NK cells, we observed variability among huNOG-EXL mice, which can be related with their very low proportion among the total FSC-A ${ }^{\text {lo }}$ $\mathrm{CD}^{-}$cells. Also of note, NK cells might be maintained in huNOG-EXL mice via IL-15 production by DCs $[25,26]$, which are efficiently engrafted in this mouse strain (see below), and could migrate to non-lymphoid tissues to exert immune surveillance [27].

Dendritic cells' development partially depends on GM-CSF [30]. Accordingly, huNOG-EXL exhibited higher frequencies of HLA-DR ${ }^{+}$Lin $1^{-}$cells (Figure 4B), where DCs are enriched. Among human DCs in blood, mDCs and pDCs constitute $60 \%-80 \%$ and $20 \%-40 \%$, respectively $[17,31]$. However, consistent with the IL-3-dependent survival of pDCs [32,33], in huNOG-EXL (transgenic 
for human IL-3), pDCs constituted the major subset of circulating DCs, with a median (range) of 93.8\% (84.4\%-100\%). Myeloid DCs comprised the $6.2 \%$ of total circulating DCs (range of $0 \%-15.6 \%$ ). The lower development of mDCs could be related to their preferential dependence on the ligand for the fms-like tyrosine kinase (Flt3), in comparison with pDCs [34,35]. Indeed, Flt3 signaling is required for $\mathrm{mDCs}$ proliferation in the periphery [36]. Nonetheless, the frequencies of circulating and SLO-confined $\mathrm{pDC}$ and $\mathrm{mDC}$ s were higher in huNOG-EXL compared with huNSG mice (Figure 4C and D). It is important to note that the predominance of PDCs in huNOG-EXL could impact the course of HIV infection or other diseases evaluated. For instance, pDCs are specialized in the release of type I interferon, which is critical for the anti-viral response and helps to polarize T-cell responses. However, pDCs are less efficient antigen-presenting cells than $\mathrm{mDC}$, which could hamper adaptive immune responses [37]. Thus, the huNOG-EXL mouse model recapitulates a pDC-predominant immune response, lacking full human DC features.

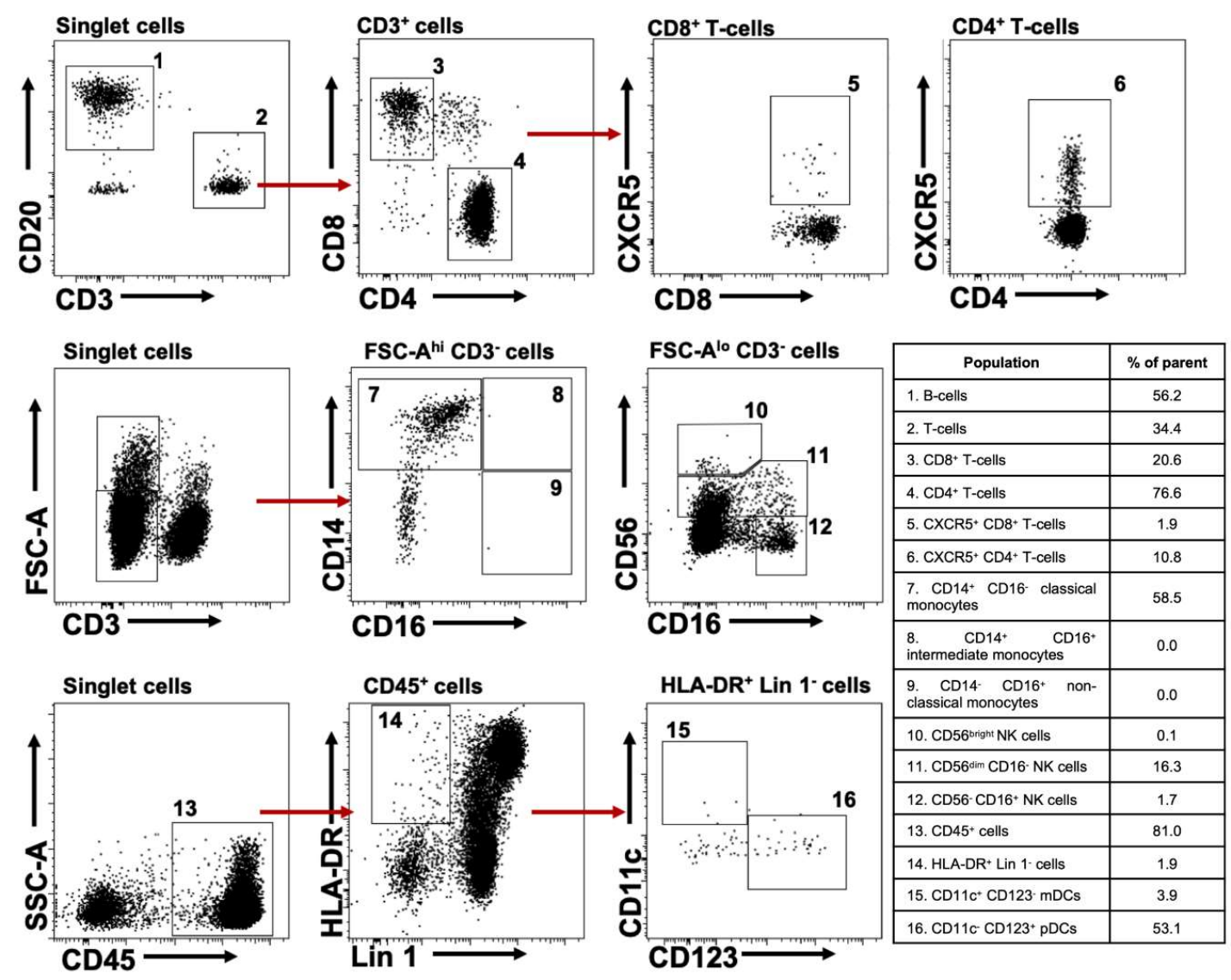

Figure 1. Cell subsets evaluated in huNOG-EXL mice. Representative gating strategy from blood cells for the identification of the cell populations evaluated. The number next to the gates represents the respective cell subset found in the adjacent table.

Monocyte and DC subsets were also evaluated from FSC-A ${ }^{\text {hi }}$ CD3 ${ }^{-}$cells. In huNOG-EXL, the major monocyte population in blood was the $\mathrm{CD} 14^{+} \mathrm{CD} 16^{-}$(classical monocytes), with non-detectable frequencies of $\mathrm{CD} 14^{+} \mathrm{CD} 16^{+}$(intermediate monocytes) and $\mathrm{CD} 14^{-} \mathrm{CD} 16^{+}$cells (classical monocytes) (Figures 1 and $4 \mathrm{~A}$, and data not shown). In addition, compared with huNSG mice, huNOG-EXL mice had higher frequencies of circulating CD14 ${ }^{+} \mathrm{CD} 16^{-}$monocytes (Figure $4 \mathrm{~A}$ ). However, the main localization of this subset was blood, with low to non-detectable frequencies in SLO (Figure 4A). These results partially agree with the reported frequencies of human monocytes in blood, where about $90 \%$ are classical monocytes and the $\mathrm{CD} 16^{+}$monocytes constitute the remaining cells [16], and with their blood residency [28]. The development of monocytes in huNOG-EXL is in accordance with the requirement of GM-CSF for monocytes/macrophages differentiation [29]. 

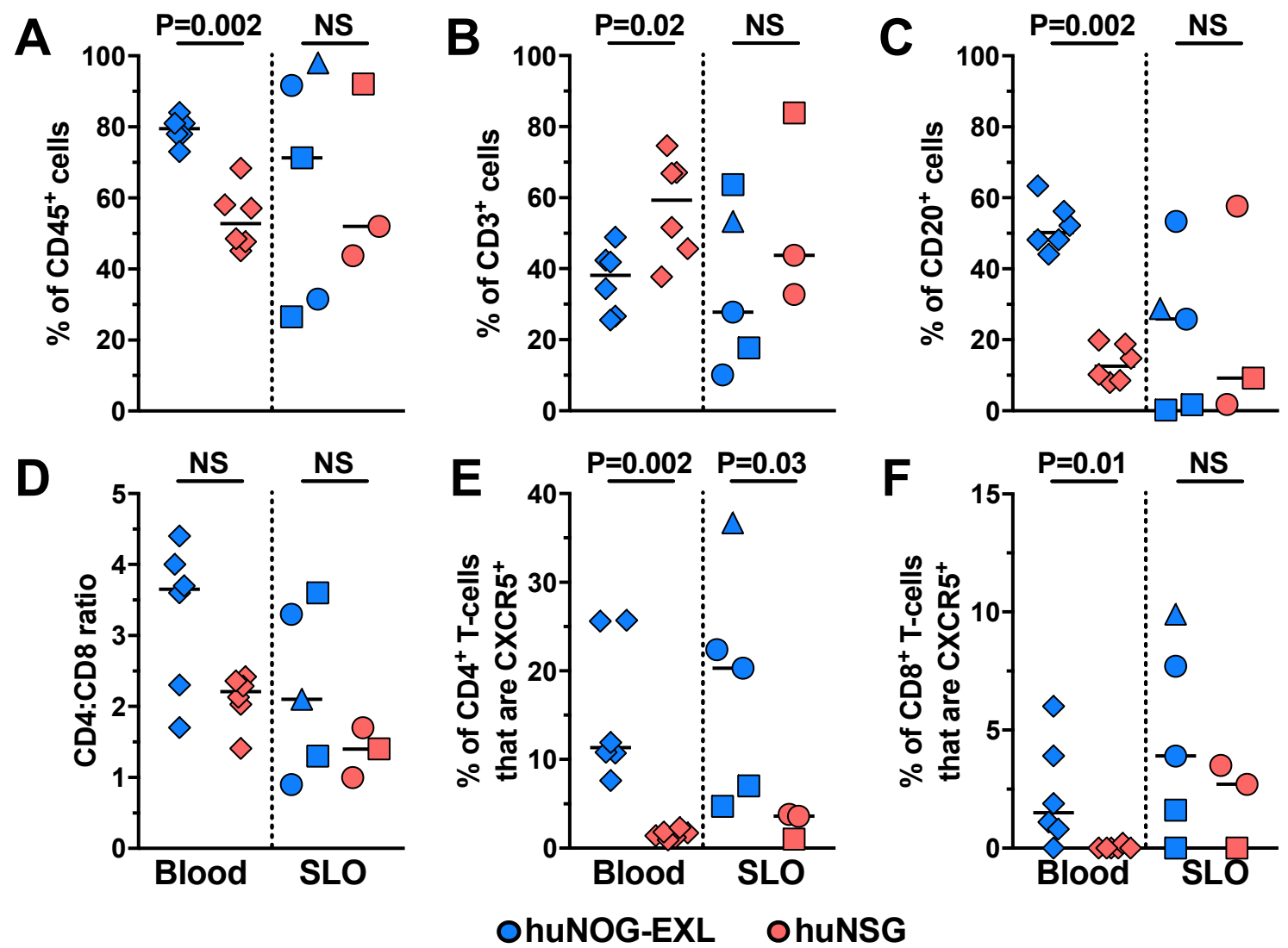

Figure 2. huNOG-EXL mice exhibit an efficient engraftment of lymphoid populations. Frequencies of $\mathrm{CD}^{+} 5^{+}(\mathbf{A}), \mathrm{CD}^{+}(\mathbf{B})$, and $\mathrm{CD} 20^{+}(\mathbf{C})$ cells from total singlet cells, the CD4:CD8 ratio (D), and the frequencies of $\mathrm{CD}^{+}(\mathrm{E})$ and $\mathrm{CD} 8^{+}$cells $(\mathrm{F})$ that are CXCR5 ${ }^{+}$in blood (diamonds) and secondary lymphoid organs (SLO; spleen: circles; axillary lymph node: squares; mesenteric lymph node: triangles) from huNOG-EXL and huNSG mice. The $p$ value of the Mann-Whitney test is shown. NS: Not statistically significant.
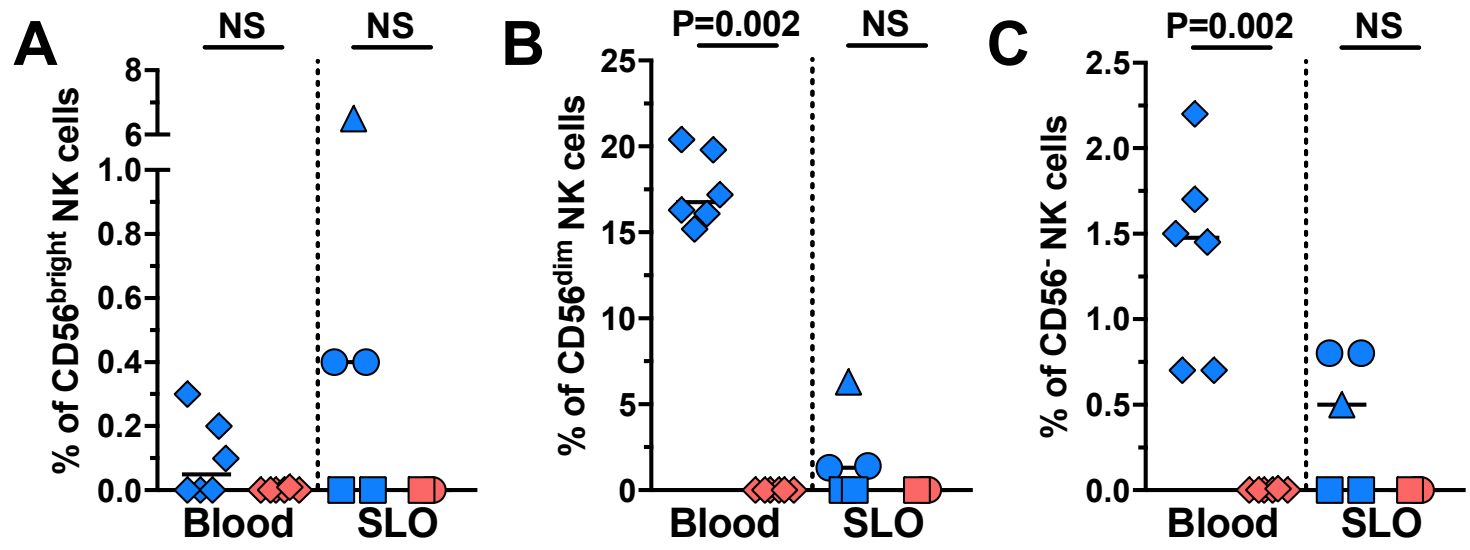

\section{OhUNOG-EXL OhUNSG}

Figure 3. huNOG-EXL mice have higher levels of NK cells than huNSG mice. Frequencies of CD56 bright (A), CD56 ${ }^{\text {dim }}$ (B), and CD56 ${ }^{-}$(C) NK cells (from FSC-A ${ }^{\text {lo }} \mathrm{CD}^{-}$cells) in blood (diamonds) and secondary lymphoid organs (SLO; spleen: circles; axillary lymph node: squares; mesenteric lymph node: triangles) from huNOG-EXL and huNSG mice. The $p$ value of the Mann-Whitney test is shown. NS: Not statistically significant. 


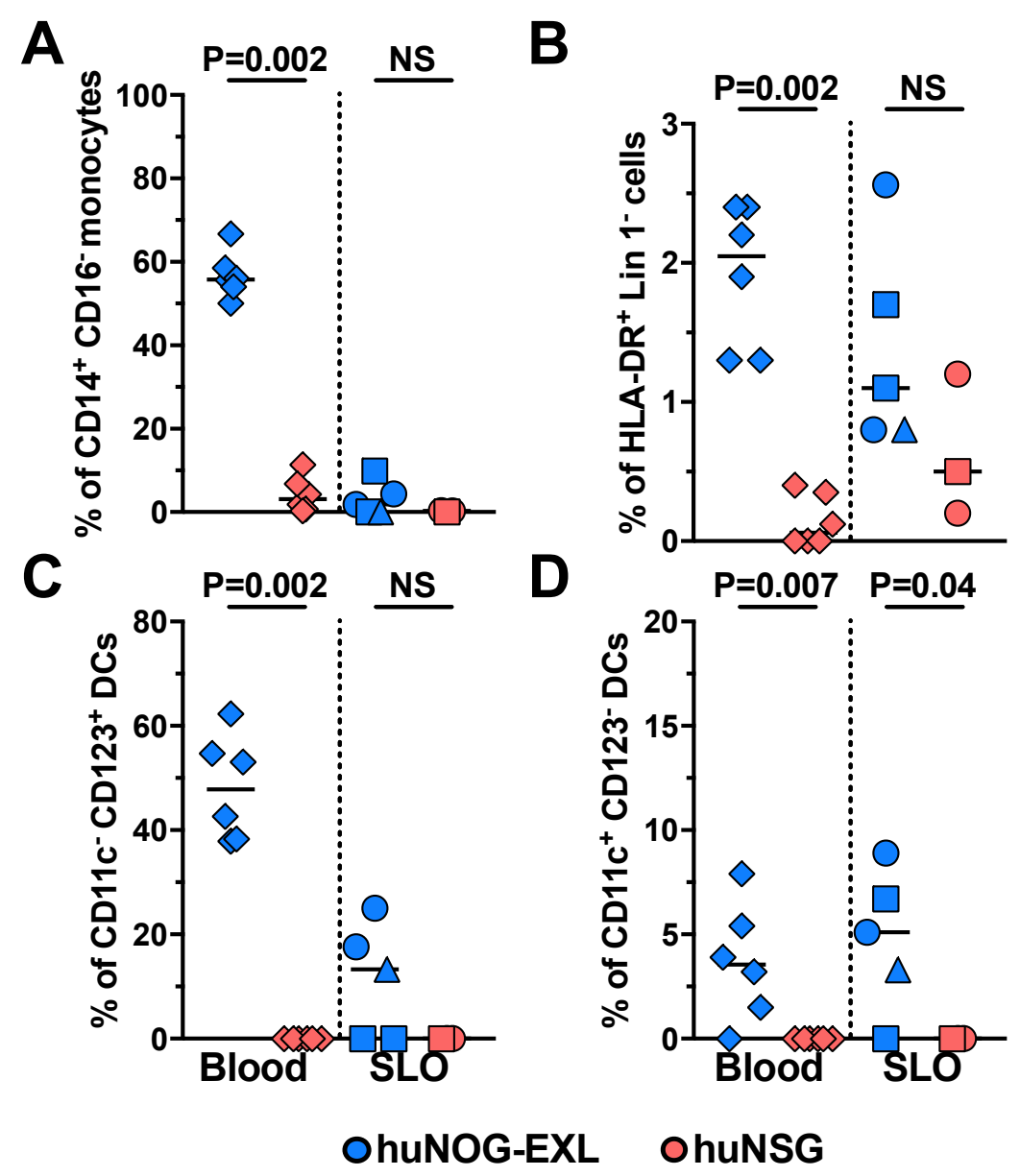

Figure 4. huNOG-EXL mice exhibit an efficient engraftment of myeloid populations. Frequencies of $\mathrm{CD} 4^{+} \mathrm{CD}_{16}{ }^{-}$(classical) monocytes from FSC-A ${ }^{\text {hi }} \mathrm{CD}^{-}$cells (A), HLA-DR ${ }^{+}$Lin $1^{-}$cells from CD45 ${ }^{+}$ cells (B), CD11c ${ }^{-} \mathrm{CD}_{123^{+}}$plasmacytoid dendritic cells $(\mathrm{C})$, and $\mathrm{CD} 11 \mathrm{c}^{+} \mathrm{CD} 123^{-}$myeloid dendritic cells (D), the latter from HLA-DR ${ }^{+}$Lin $1^{-}$cells, in blood (diamonds) and secondary lymphoid organs (SLO; spleen: circles; axillary lymph node: squares; mesenteric lymph node: triangles) from huNOG-EXL and huNSG mice. The $p$ value of the Mann-Whitney test is shown. NS: Not statistically significant.

In summary, compared with huNSG mice, huNOG-EXL exhibited higher levels of engraftment, as well as higher frequencies of lymphoid and myeloid populations, both in blood and SLO.

\subsection{HIV Replication in huNOG-EXL Mice}

Previous reports have demonstrated that huNOG mice support HIV replication [38-40]. However, to our knowledge, this is the first report evaluating HIV infection dynamics in huNOG-EXL mice. We determined the response of huNOG-EXL mice to an intraperitoneal HIV challenge with 15,000 Median Tissue Culture Infectious Dose $\left(\mathrm{TCID}_{50}\right.$ ) units of the CCR5-tropic HIV reference BaL strain. As shown in Figure 5A, HIV-infected huNOG-EXL dramatically increased the viral load between the first and third weeks post-infection, with a stable viral load in the subsequent weeks of monitoring. As expected, no viral load was detected in uninfected mice. The increase in the viral load coincided with the decrease in the frequency of $\mathrm{CD}^{4} 5^{+}$cells in blood (Figure 5B), consistent with viral-induced suppression of the human hematopoietic progenitor cells [12]. In addition, there was an inversion of the CD4:CD8 ratio, reaching levels below 1 (Figure 5C), consistent with the decrease in the proportion of $\mathrm{CD} 4^{+} \mathrm{T}$-cells due to a cytopathic viral effect. These changes were not observed in uninfected mice (Figure 5A-C). Importantly, the kinetics of HIV replication and decrease in the level of engraftment and CD4:CD8 ratio in huNOG-EXL mice were similar to those in HIV-infected huNSG mice (Figure 5D-F), 
and comparable to previous reports [12,13], although HIV-infected huNOG-EXL mice exhibited higher viral loads than huNSG mice in weeks $1-3$ ( $p \leq 0.009$, data not shown). Thus, huNOG-EXL supports HIV replication.
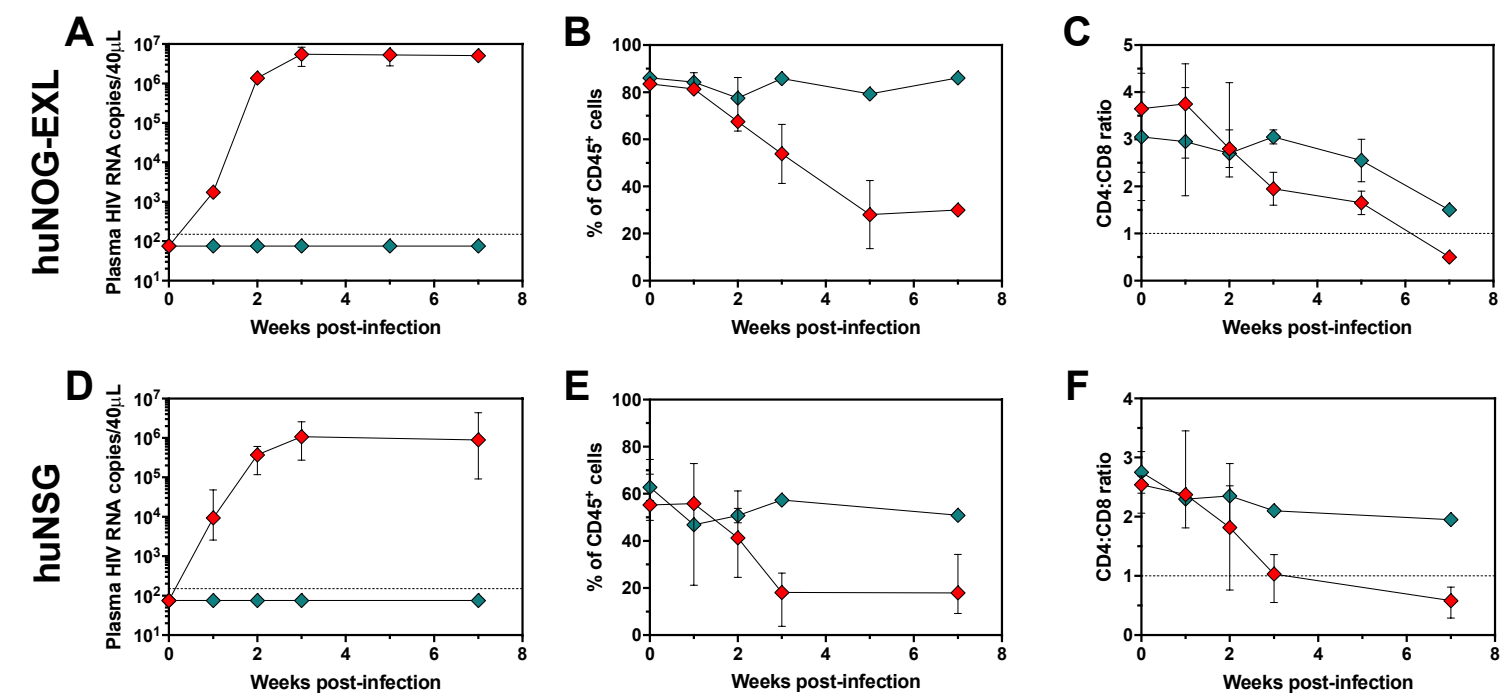

Figure 5. huNOG-EXL mice support the replication of HIV, with the consequent decrease in the level of engraftment and inversion of the CD4:CD8 ratio. Viral load (A,D), blood frequencies of CD45 ${ }^{+}$cells (B,E), and blood CD4:CD8 ratio (C,F) in huNOG-EXL (A-C) and huNSG (D-F) mice after infection with HIV (green diamonds: uninfected mice; red diamonds: HIV-infected mice). In A and $\mathbf{D}$, the dashed lines indicate the limit of detection of the assay. In $\mathbf{C}$ and $\mathbf{F}$, the dashed lines indicate the CD4:CD8 ratio $=1$.

\subsection{Changes in Cell Populations along HIV Infection Time in huNOG-EXL Mice}

We explored the changes that undergo lymphoid and myeloid cell populations in HIV-challenged huNOG-EXL mice along infection time, both in blood and SLO. We also compared the proportions of each cell subset between infected and uninfected huNOG-EXL mice at weeks 3, 5, and 7 post-infection, when the viral load had reached its peak and subsequently remained stable (Figure $5 \mathrm{~A}$ ). The frequencies of circulating T-cells and B-cells decreased along infection time in HIV-challenged mice (Figure 6A,B, left and middle panels), but not in SLO (Figure 6A,B, right panels). These results are consistent with the cytopathic viral effect [41], activation-induced cell death [42], and/or virus-induced cell migration to SLO [43-46]. Indeed, B-cells depletion in HIV is associated with increased susceptibility to CD95 ligand-mediated cell death [47], as well as intrinsic apoptosis [48]. CXCR5 ${ }^{+}$CD4 ${ }^{+}$T-cells, both circulating and follicle-confined, are relevant in HIV infection as they are a major target of this virus, constitute the main viral reservoir $[49,50]$, and they have been found decreased in blood $[51,52]$ but expanded in lymph nodes from HIV-infected patients [53]. However, there were no differences in the frequencies of $\mathrm{CXCR}^{+}{ }^{+} \mathrm{CD} 4^{+}$T-cells between HIV-infected and uninfected huNOG-EXL mice, both in blood and SLO (Figure 6C). In contrast, similar to previous human reports [54], the frequencies of circulating CXCR5 ${ }^{+} \mathrm{CD}^{+}$T-cells were lower in HIV-infected huNOG-EXL mice compared with uninfected controls (Figure 6D, left and middle panels), but their frequency was higher in SLO (Figure $6 \mathrm{D}$ right panel), consistent with the recruitment of $\mathrm{CXCR} 5^{+} \mathrm{CD} 8^{+} \mathrm{T}$-cells in SLO during HIV infection [55]. 
Blood

kinetics

A

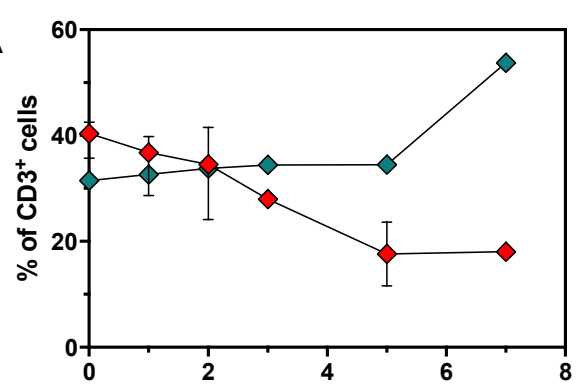

B

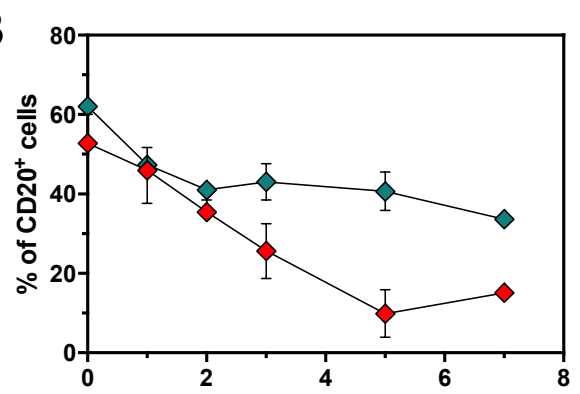

C

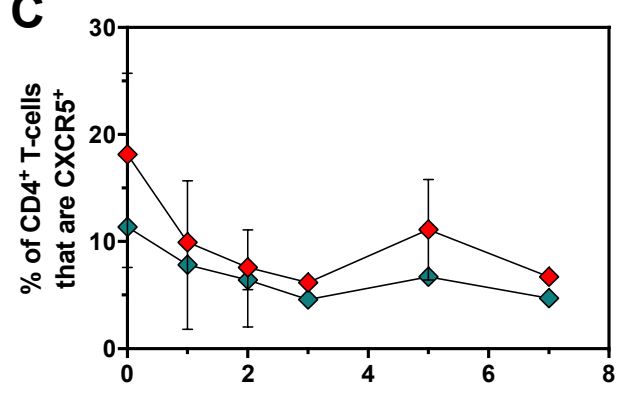

D

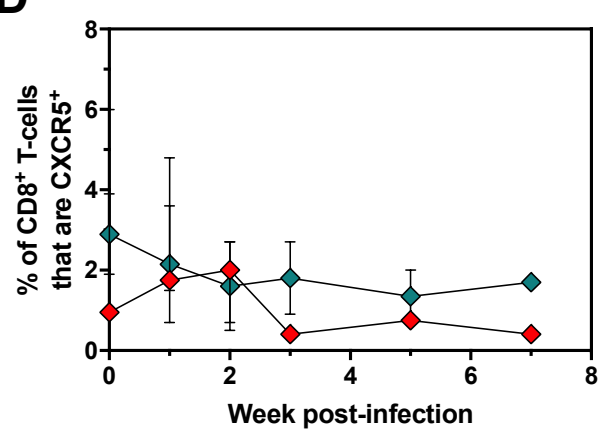

Blood

weeks $3,5,7$
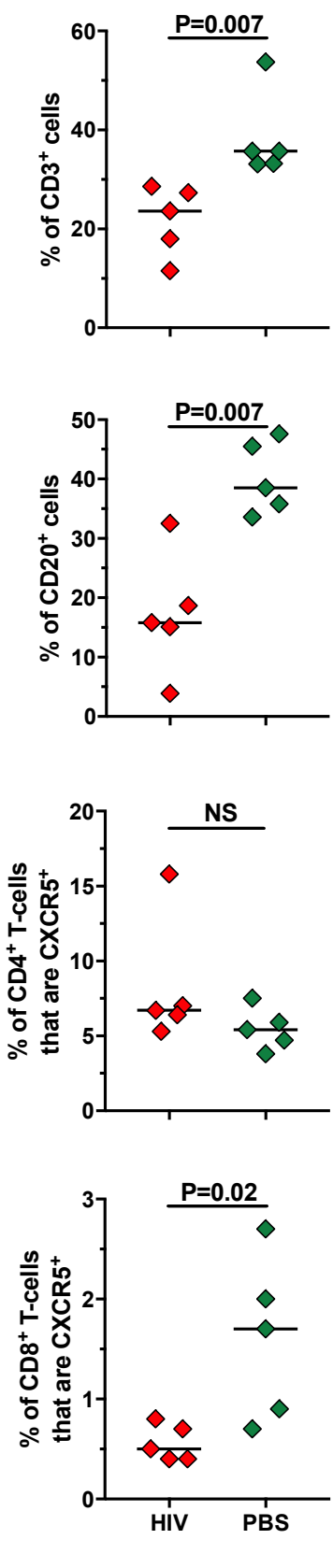
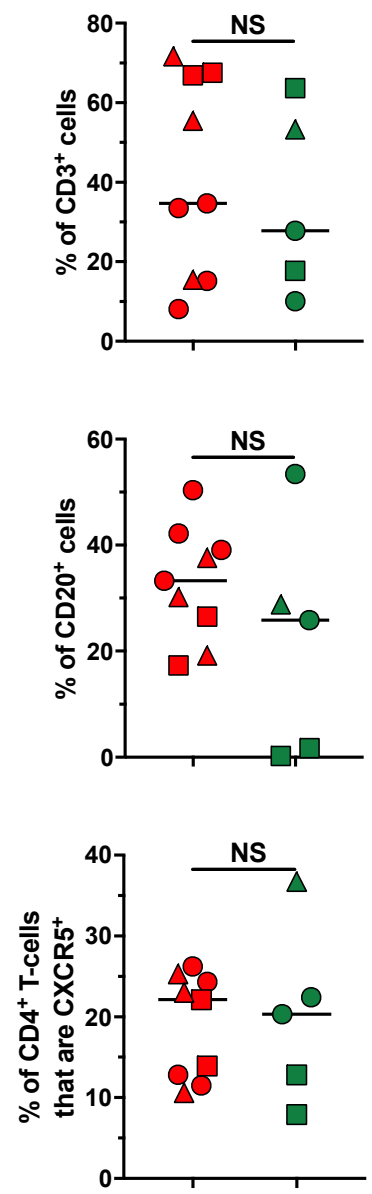

SLO

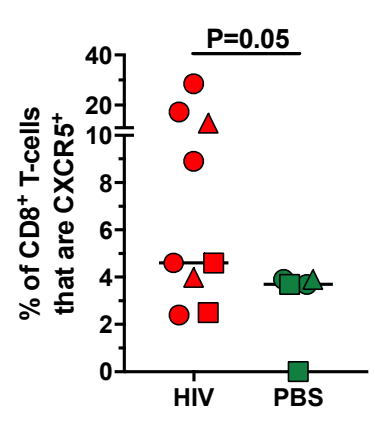

Figure 6. HIV infection in huNOG-EXL mice induces the decrease of circulating T-cells, B-cells, and $\mathrm{CXCR} 5^{+} \mathrm{CD} 8^{+} \mathrm{T}$-cells. Frequencies of $\mathrm{CD}^{+}$cells $(\mathrm{A})$ and $\mathrm{CD} 20^{+}$cells $(\mathbf{B})$ from total singlet cells, $\mathrm{CXCR}^{+} \mathrm{CD}^{+} \mathrm{T}$-cells $(\mathrm{C})$, and CXCR5 ${ }^{+} \mathrm{CD} 8^{+} \mathrm{T}$-cells (D) from total CD4 ${ }^{+}$and $\mathrm{CD} 8^{+} \mathrm{T}$-cells, respectively, in huNOG-EXL mice after infection with HIV. In the left panels, the kinetics of blood populations are shown; in the middle panels, comparisons of blood populations between infected and uninfected mice in compiled data from 3, 5, and 7 weeks post-infection are shown; in the right panels, comparisons of secondary lymphoid organs (SLO; spleen: circles; axillary lymph node: squares; mesenteric lymph node: triangles)-confined populations between infected and uninfected mice are shown. In all the cases, green: uninfected mice; red: HIV-infected mice. The $p$ value of the Mann-Whitney test is shown. 
Myeloid subsets also suffered some changes in HIV-challenged huNOG-EXL mice. Similar to previous human reports [56], the frequencies of circulating $\mathrm{CD} 14^{+} \mathrm{CD} 16^{-}$classical monocytes decreased in infected huNOG-EXL mice compared with uninfected controls (Figure 7A, left and middle panels). Consistent with their low frequency in SLO (Figure 4A), there were no differences between infected and uninfected mice in the frequencies of classical monocytes in SLO (Figure 7A, right panel). Of note, the decrease in the proportion of classical monocytes in HIV-infected mice was not due to the increase of intermediate or non-classical monocytes, which remained at non-detectable proportions along infection time (data not shown). Probably, the decrease in classical monocytes is mediated by indirect mechanisms, since this subset is partially resistant to HIV infection, in comparison with macrophages $[57,58]$. Loss of CD14 upon monocyte activation may also account for the decrease in the proportion of these cells [59]. Nonetheless, a minor fraction of HIV-infected monocytes could constitute a latent viral reservoir [60].

Contrary to classical monocytes, the proportion of HLA-DR ${ }^{+}$Lin $1^{-}$cells in HIV-infected huNOG-EXL mice increased in blood along infection time (Figure 7B, left and middle panels), but decreased in SLO (Figure 7B, right panel), consistent with an egress of these cells to peripheral blood with infection in an attempt to restore the mature DC pool, or transitory migration to inflamed tissues [61]. Nonetheless, similar to previous human reports [62,63], we observed decreased frequencies of circulating pDCs and conserved frequencies of this subset in SLO (Figure 7C). There were no differences in the frequencies of mDCs between infected and uninfected huNOG-EXL mice (data not shown). The increase in HLA-DR ${ }^{+}$Lin $1^{-}$cells in HIV-infected huNOG-EXL mice occurred at expenses of $\mathrm{CD} 11 \mathrm{c}^{-} \mathrm{CD} 123^{-}$immature cells, since, in comparison with uninfected controls, they exhibited higher frequencies of this subset in blood (median [range] of 68.2 [45.5-87.5] vs. 42.8 [34.1-54.7], $p=0.01$; data not shown), and lower frequencies in SLO (median [range] of 72.8 [38.4-90] vs. 83.4 [69.9-100], $p=0.04$; data not shown). Thus, similar to previous human reports [64], HLA-DR ${ }^{+}$Lin $1^{-}$ cells increase in blood from huNOG-EXL mice at expenses of the increase of CD11c ${ }^{-}$CD123- immature cells [65], whereas there is a decrease in the proportion of pDCs, which could be associated with viral infection and impaired function [66].

Lastly, we evaluated the changes in NK cell subsets. As shown in Figure 7D, contrary to previous human reports [67], there were no differences in the proportion of CD56 ${ }^{\mathrm{dim}} \mathrm{NK}$ cells between HIV-infected and uninfected huNOG-EXL mice. However, there was a decrease in the proportion of circulating CD56 ${ }^{\text {bright }}$ NK cells in HIV-infected huNOG-EXL mice (Figure 7E left and middle panels), but not in SLO (Figure 7E, right panel). Finally, there were no differences in the frequencies of CD56NK cells between HIV-infected and uninfected huNOG-EXL mice (data not shown). Considering the ability of CD56 $6^{\text {bright }}$ NK cells to produce anti-viral cytokines, such as interferon- $\gamma$ [15], their decrease could impair the activation of adaptive immune cells and enhance viral replication. Indeed, HIV infection induces phenotypic and functional changes of CD56 $6^{\text {bright }} \mathrm{NK}$ cells, which are associated with higher viral loads [68]. 

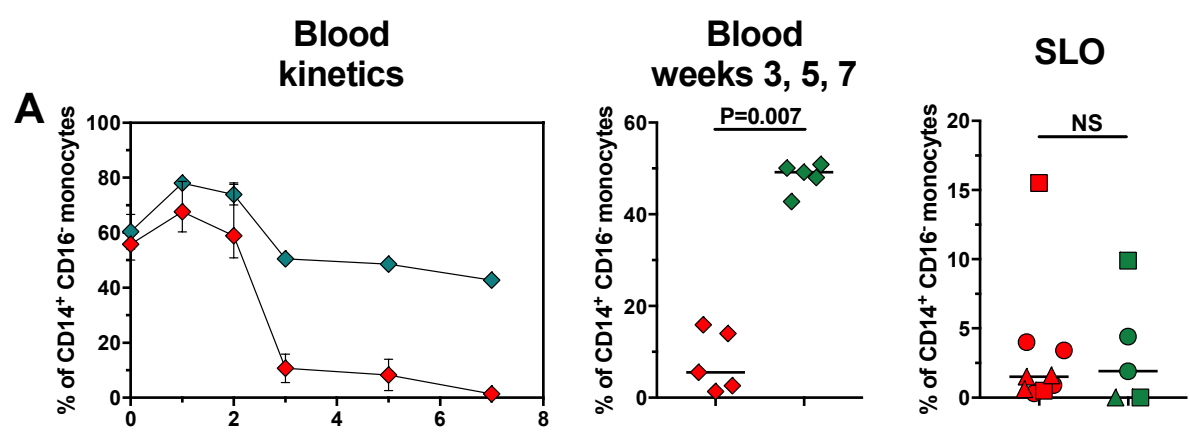

B
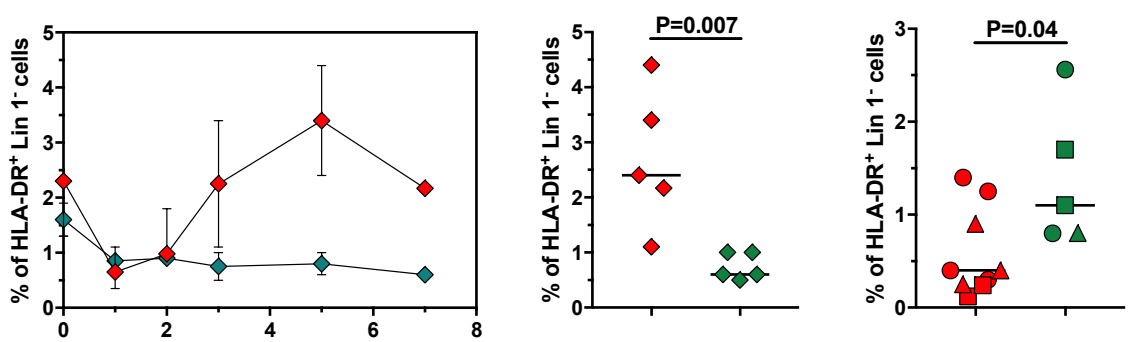

C
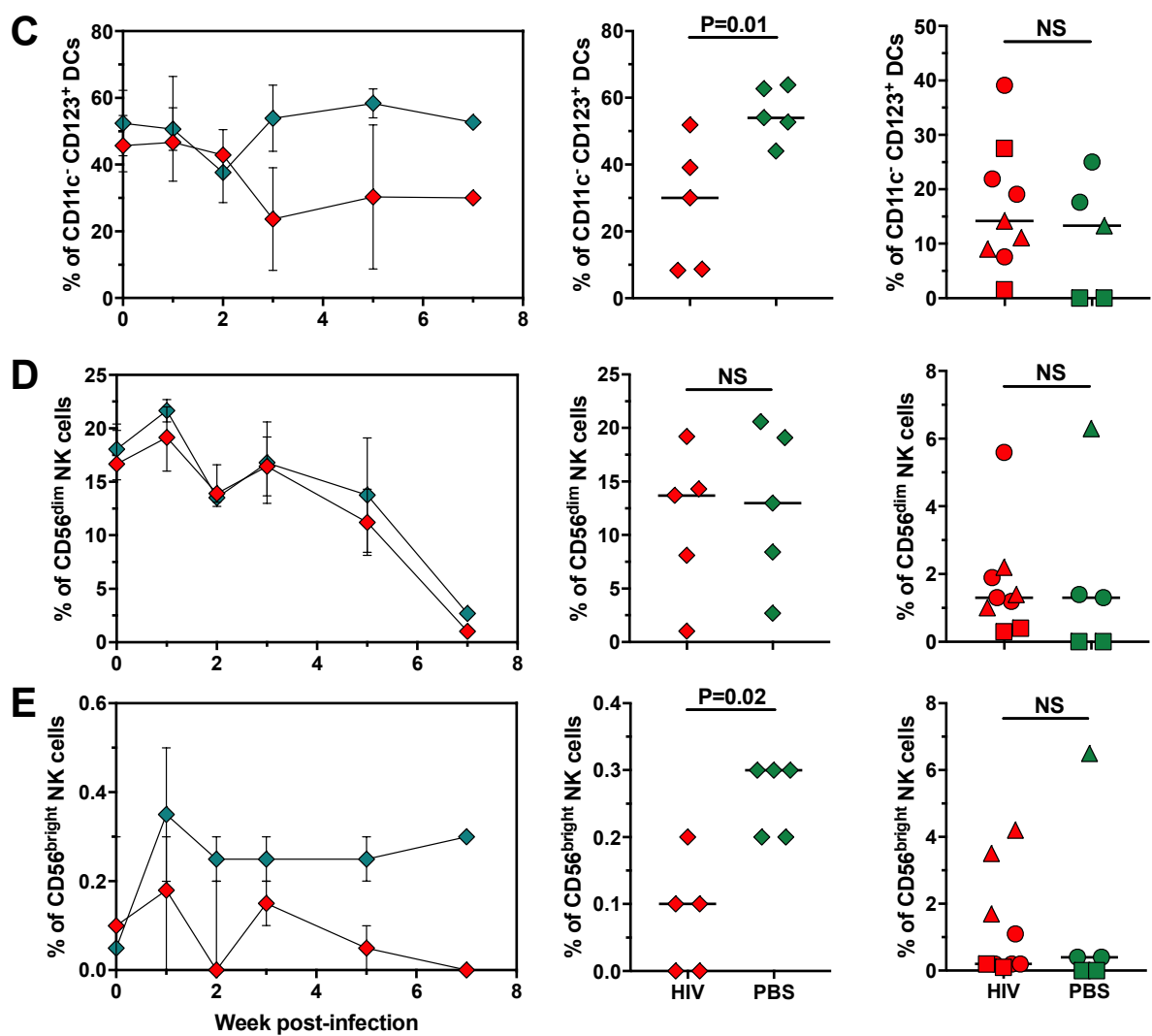

Figure 7. HIV infection in huNOG-EXL mice affects the frequencies of classical monocytes, dendritic cells, and CD56 $6^{\text {bright }} \mathrm{NK}$ cells. Frequencies of $\mathrm{CD} 14^{+} \mathrm{CD}^{-} 6^{-}$(classical) monocytes from FSC-A ${ }^{\text {hi }}$ $\mathrm{CD}^{-}$cells (A), HLA-DR ${ }^{+}$Lin $1^{-}$cells from $\mathrm{CD}^{-} 5^{+}$cells $(\mathbf{B}), \mathrm{CD}_{11} \mathrm{c}^{-} \mathrm{CD} 123^{+}$plasmacytoid dendritic cells from HLA-DR ${ }^{+}$Lin $1^{-}$cells (C), CD56 ${ }^{\mathrm{dim}}(\mathrm{D})$, and CD56 $6^{\text {bright }} \mathrm{NK}$ cells (E), the latter from FSC-A ${ }^{\text {lo }} \mathrm{CD}^{-}$cells, in huNOG-EXL mice after infection with HIV. In the left panels, the kinetics of blood populations are shown; in the middle panels, comparisons of blood populations between infected and uninfected mice in compiled data from 3, 5, and 7 weeks post-infection are shown; in the right panels, comparisons of secondary lymphoid organs (SLO; spleen: circles; axillary lymph node: squares; mesenteric lymph node: triangles)-confined populations between infected and uninfected mice are shown. In all the cases, green: uninfected mice; red: HIV-infected mice. The $p$ value of the Mann-Whitney test is shown. 


\subsection{The Changes in Lymphoid and Myeloid Cells are Associated with the Level of HIV Replication in huNOG-EXL Mice}

Together, the results presented here indicate that HIV infection induces changes in the proportions of circulating and SLO-confined lymphoid and myeloid populations. Of note, most of the changes occurred concomitantly with the increase in the viral load (from 1 to 3 weeks post-infection), and subsequently remained stable throughout the remaining monitoring time. This suggest that most of the alterations in human immune cell populations occur in an early phase of the infection and are maintained throughout the time while active HIV replication is present. Further, we analyzed the relationship between HIV replication and the changes in the cell subsets evaluated in blood and SLO. As shown in Table 1, the frequencies of circulating $\mathrm{CD}^{4} 5^{+}$cells, B-cells, $\mathrm{CD} 14^{+} \mathrm{CD} 16^{-}$classical monocytes, $\mathrm{CD} 11 \mathrm{c}^{-} \mathrm{CD} 123^{+} \mathrm{pDCs}$, and $\mathrm{CD} 56^{\text {bright }} \mathrm{NK}$ cells, as well as the $\mathrm{CD} 4 \mathrm{CD} 8$ ratio, were negatively correlated with the plasma viral load. Interestingly, a positive correlation was found between the frequency of blood HLA-DR ${ }^{+}$Lin $1^{-}$cells and plasma viral load (Table 1), whereas there was a negative correlation when ALN-confined HLA-DR ${ }^{+}$Lin $1^{-}$cells were evaluated, consistent with a viral-induced increase in the proportion of this subset (mainly constituted by immature cells) in blood. In addition, the frequency of spleen CXCR5 ${ }^{+} \mathrm{CD} 8^{+} \mathrm{T}$-cells positively correlated with plasma viral load (Table 1), suggesting that HIV replication, antigen levels, and/or a local inflammatory milieu induces the recruitment of this subset to SLO, as previously reported [55]. Finally, there was no correlation between the frequency of circulating total T-cells (Table 1), or other circulating or SLO-confined subsets (data not shown), and viral load. Altogether, these results support that the changes in several lymphoid and myeloid populations are associated with HIV replication, a product of active replication, bystander activation-induced cell death, or impaired cell maturation/differentiation. Cell redistribution in response to different antigenic burdens in lymphoid tissues may also drive the decrease in circulating populations. Certainly, huNOG-EXL mice gives relevant information regarding cellular dynamics during HIV infection.

Table 1. Correlations between viral load and cell populations in blood and SLO.

\begin{tabular}{|c|c|c|c|}
\hline \multicolumn{2}{|c|}{ Correlations Plasma Viral Load vs. Cell Populations } & \multicolumn{2}{|c|}{ Spearman Test } \\
\hline Compartment ${ }^{1}$ & Population & rho & $p$ Value \\
\hline Blood & CD $45^{+}$cells & -0.89 & 0.0005 \\
\hline Blood & $\mathrm{CD}^{+}{ }^{\mathrm{T}}$-cells & -0.3 & 0.1 \\
\hline Blood & CD20 ${ }^{+}$B-cells & -0.85 & 0.02 \\
\hline Blood & CD4:CD8 ratio & -0.66 & 0.02 \\
\hline Spleen & $\mathrm{CXCR}^{+} \mathrm{CD}^{+} \mathrm{T}$-cells & 0.92 & 0.02 \\
\hline Blood & HLA-DR ${ }^{+}$Lin $1^{-}$cells & 0.91 & 0.0004 \\
\hline Axillary lymph node & HLA-DR ${ }^{+}$Lin $1^{-}$cells & -0.73 & 0.07 \\
\hline Blood & $\mathrm{CD} 14^{+} \mathrm{CD}^{-} 6^{-}$classical monocytes & -0.88 & 0.001 \\
\hline Blood & 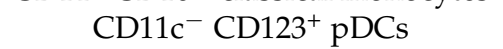 & -0.87 & 0.002 \\
\hline Blood & CD56 ${ }^{\text {bright }}$ NK cells & -0.72 & 0.02 \\
\hline
\end{tabular}

\section{Conclusions}

Our results indicate that huNOG-EXL mice support HIV replication and recapitulate several viral-induced changes of human cell populations, such as the decrease in T-cells, B-cells, classical monocytes, and DCs. Thanks to the expression of human IL-3 and GM-CSF, huNOG-EXL mice exhibit enhanced and stable engraftment of myeloid populations. Thus, this model offers the possibility, in addition to the typical kinetics of viral replication and observable effects of anti-viral drugs, of studying other cell populations, which are not efficiently generated in other non-transgenic mouse strains, such as monocytes, macrophages, or DCs, that are relevant in the setting of HIV infection as viral reservoirs. The higher content of antigen-presenting cells in huNOG-EXL mice also allows myeloid-lymphoid cell interactions and potentially better adaptive immune responses. Nonetheless, 
some limitations were observed in the huNOG-EXL mouse model, such as the reconstitution of classical, but no other monocytes subsets, and a predominance of pDCs instead of mDCs. Thus, these issues should be considered for further studies evaluating HIV or other diseases.

\section{Materials and Methods}

\subsection{Ethics Statement}

All animal care and procedures were performed according to protocols reviewed and approved by the Institutional Animal Care and Use Committee (IACUC) at the University of Maryland School of Medicine. Mice were monitored daily for morbidity and mortality, as previously reported [10].

\subsection{Generation and HIV Infection of Humanized Mice}

NOD.Cg-Prkdc scid Il2rgtm1Sug Tg(SV40/HTLV-IL3,CSF2)10-7Jic/JicTac (NOG-EXL) mice were kindly provided by Taconic Biosciences $(\mathrm{n}=6)$. NOD.Cg-Prkcd ${ }^{\text {scid }} I L 2 \mathrm{rg}^{\mathrm{tm} l \mathrm{Wij}} / \mathrm{SzJ}$ (NSG) mice were purchased from The Jackson Laboratory $(n=12)$. One to three-weeks old age female NOG-EXL and newborn NSG mice were gamma irradiated and engrafted with $1.2 \times 10^{5}$ human umbilical cord blood-derived CD34 ${ }^{+}$hematopoietic stem cells (HSCs), obtained from a commercial provider, i.v. via the tail vein (NOG-EXL mice) or via intrahepatic injection (NSG mice). Mice were maintained with husbandry conditions and microbiological monitoring practices. Ten to fourteen weeks post-engraftment, mice were checked for human leukocyte reconstitution by flow cytometry. Mice with more than $25 \%$ of human $\mathrm{CD}_{4} 5^{+}$cells were intraperitoneally infected with $15,000 \mathrm{TCID}_{50}$ units of the CCR5-tropic HIV reference BaL strain. Uninfected mice were included as controls. After infection, mice were consecutively euthanized every two weeks to obtain secondary lymphoid organs (SLO), by $\mathrm{CO}_{2}$ asphyxiation followed by cervical dislocation.

\subsection{Flow Cytometry}

Peripheral blood (drawn from the retroorbital vein), spleen and lymph node mononuclear cells were obtained from mice (the latter when were available). Tissue samples were collected at necropsy and processed immediately in a $70 \mu \mathrm{m}$-pore size nylon cell strainer (Corning), followed by mononuclear cell isolation through a Ficoll density gradient (GE Healthcare). Remaining red blood cells were lysed with ACK buffer (Quality Biological Inc., Gaithersburg, MD, USA). For flow cytometry analysis, cells were incubated for 20 minutes at room temperature with optimized doses of the following anti-human antibodies: (i) T-cell/B-cell panel: CD3 APC (clone UCHT1, Biolegend), CD4 Alexa Fluor (AF) 488 (clone OKT4, Biolegend), CD8 AF 700 (clone OKT8, Thermo Fisher), CXCR5 PerCP Cy5.5 (clone RF8B2, BD), CD20 Brilliant Violet (BV) 605 (clone 2H7, Biolegend); (ii) Monocytes/NK cell panel: CD3 AF 700 (clone UCHT1, Biolegend), CD14 PE Cy7 (clone 63D3, Biolegend), CD16 APC-H7 (clone 3G8, BD Pharmingen), CD56 BV510 (clone 5.1H11, Biolegend); (iii) Dendritic cell panel: CD45 BV421 (clone 2D1, Biolegend), Lineage 1 cocktail FITC (CD3 [clone UCHT1], CD14 [clone HCD14], CD16 [clone 3G8], CD19 [clone HIB19], CD20 [clone 2H7] and CD56 [clone HCD56]; Biolegend), CD123 PE (clone 6H6, Biolegend), CD1c PE Cy7 (clone L161, Biolegend), HLA-DR PerCP Cy5.5 (clone LN3, Biolegend), CD11c BV605 (clone 3.9, Biolegend). After incubation, red cells from peripheral blood were lysed with BD FACS Lysing Solution (BD), and all samples were washed twice with FACS buffer (1\% Fetal Bovine Serum in 1X PBS). Finally, cells were fixed with 1\% paraformaldehyde in 1 X PBS, and acquired on a FACSAria II cytometer (BD) within an hour of completing the staining. Data were analyzed with the FlowJo Software version 8.7 (Tree Star, Inc., Ashland, OR, USA).

\subsection{Determination of Viral Load}

Plasma was obtained for quantification of HIV RNA copy number by an in-house real-time RT-PCR, using HIV gag primers, SK38/SK39 and SYBR green dyes, as previously reported [10,11]. The assay has a sensitivity of $150 \mathrm{HIV}$ RNA copies / $40 \mu \mathrm{L}$ plasma. 


\subsection{Statistical Analysis}

GraphPad Prism software v. 7.0 (GraphPad Software, La Jolla, CA, USA) was used for statistical analysis. Data are presented as medians and ranges. The Mann-Whitney test was used for comparison of 2 independent data. The degree of correlation between variables was determined with the Spearman test. In all the analyses, a value equal to the half of the limit of detection of the assay was assigned to samples with non-detectable viral load. In all cases, a $p$ value $<0.05$ was considered significant.

Author Contributions: Conceptualization, S.M.-M. and J.C.Z.; methodology, F.P.-C., S.M.-M., and J.C.Z.; software and formal analysis F.P.-C.; investigation, F.P.-C., S.M.-M., and J.C.Z.; resources, IHV animal facility internal funds; data curation, F.P.-C., S.M.-M. and J.C.Z.; writing-original draft preparation F.P.-C.; writing-review and editing, F.P.-C., S.M.-M., J.B., H.D., and J.C.Z.; visualization, F.P.-C.; supervision, J.C.Z.; project administration, J.C.Z., S.M.-M. and H.D.; funding acquisition, J.B., and H.D.

Funding: This research was funded by IHV animal facility internal funds and NOG-EXL mice were provided by Taconic Biosciences. Salary support for SMM, HD, JB, and JCZ came from the Institute of Human Virology (IHV), University of Maryland School of Medicine. FPC was supported by the Universidad de Antioquia, Corporacion Universitaria Remington, and Fundacion Sapiencia in Medellin, Colombia for an 8-month research position at the Institute of Human Virology of the University of Maryland School of Medicine Baltimore, USA.

Acknowledgments: The author would like to acknowledge Taconic Biosciences for they kind donation of NOG-EXL mice used on this study.

Conflicts of Interest: The authors declare no conflict of interest. The funders had no role in the design of the study; in the collection, analyses, or interpretation of data; in the writing of the manuscript, or in the decision to publish the results.

\section{References}

1. Malim, M.H.; Bieniasz, P.D. HIV restriction factors and mechanisms of evasion. Cold Spring Harb. Perspect. Med. 2012, 2, a006940. [CrossRef] [PubMed]

2. Masse-Ranson, G.; Mouquet, H.; Di Santo, J.P. Humanized mouse models to study pathophysiology and treatment of HIV infection. Curr. Opin. HIV AIDS 2018, 13, 143-151. [CrossRef] [PubMed]

3. Estes, J.D.; Wong, S.W.; Brenchley, J.M. Nonhuman primate models of human viral infections. Nat. Rev. Immunol. 2018, 18, 390-404. [CrossRef] [PubMed]

4. Victor Garcia, J. Humanized mice for HIV and AIDS research. Curr. Opin. Virol. 2016, 19, 56-64. [CrossRef] [PubMed]

5. Billerbeck, E.; Barry, W.T.; Mu, K.; Dorner, M.; Rice, C.M.; Ploss, A. Development of human CD4+FoxP3+ regulatory $\mathrm{T}$ cells in human stem cell factor-, granulocyte-macrophage colony-stimulating factor-, and interleukin-3-expressing NOD-SCID IL2R??null humanized mice. Blood 2011, 117, 3076-3086. [CrossRef] [PubMed]

6. Ito, M.; Hiramatsu, H.; Kobayashi, K.; Suzue, K.; Kawahata, M.; Hioki, K.; Ueyama, Y.; Koyanagi, Y.; Sugamura, K.; Tsuji, K.; et al. NOD/SCID/ $\gamma$ cnull mouse: An excellent recipient mouse model for engraftment of human cells. Blood 2002, 100, 3175-3182. [CrossRef] [PubMed]

7. Ito, R.; Takahashi, T.; Katano, I.; Kawai, K.; Kamisako, T.; Ogura, T.; Ida-Tanaka, M.; Suemizu, H.; Nunomura, S.; Ra, C.; et al. Establishment of a human allergy model using human IL-3/GM-CSF-transgenic NOG mice. J. Immunol. 2013, 191, 2890-2899. [CrossRef] [PubMed]

8. Shultz, L.D.; Lyons, B.L.; Burzenski, L.M.; Gott, B.; Chen, X.; Chaleff, S.; Kotb, M.; Gillies, S.D.; King, M.; Mangada, J.; et al. Human lymphoid and myeloid cell development in NOD/LtSz-scid IL2R gamma null mice engrafted with mobilized human hemopoietic stem cells. J. Immunol. 2005, 174, 6477-6489. [CrossRef]

9. Shultz, L.D.; Ishikawa, F.; Greiner, D.L. Humanized mice in translational biomedical research. Nat. Rev. Immunol. 2007, 7, 118. [CrossRef]

10. Medina-Moreno, S.; Dowling, T.C.; Zapata, J.C.; Le, N.M.; Sausville, E.; Bryant, J.; Redfield, R.R.; Heredia, A. Targeting of CDK9 with indirubin 3'-monoxime safely and durably reduces HIV viremia in chronically infected humanized mice. PLoS ONE 2017, 12, e0183425. [CrossRef]

11. Heredia, A.; Le, N.; Gartenhaus, R.B.; Sausville, E.; Medina-Moreno, S.; Zapata, J.C.; Davis, C.; Gallo, R.C.; Redfield, R.R. Targeting of mTOR catalytic site inhibits multiple steps of the HIV-1 lifecycle and suppresses HIV-1 viremia in humanized mice. Proc. Natl. Acad. Sci. USA 2015, 112, 9412-9417. [CrossRef] [PubMed] 
12. Araínga, M.; Su, H.; Poluektova, L.Y.; Gorantla, S.; Gendelman, H.E. HIV-1 cellular and tissue replication patterns in infected humanized mice. Sci. Rep. 2016, 6, 23513. [CrossRef] [PubMed]

13. Satheesan, S.; Li, H.; Burnett, J.C.; Takahashi, M.; Li, S.; Wu, S.X.; Synold, T.W.; Rossi, J.J.; Zhou, J. HIV replication and latency in a humanized NSG mouse model during suppressive oral combinational ART. J. Virol. 2018, 92, e02118-17. [CrossRef]

14. Rochat, M.-A.; Schlaepfer, E.; Kuster, S.P.; Li, D.; Audige, A.; Ivic, S.; Fahrny, A.; Speck, R.F. Monitoring HIV DNA and cellular activation markers in HIV-infected humanized mice under cART. Virol. J. 2018, 15, 191. [CrossRef]

15. Flórez-Álvarez, L.; Hernandez, J.C.; Zapata, W. NK Cells in HIV-1 Infection: From Basic Science to Vaccine Strategies. Front. Immunol. 2018, 9, 2290. [CrossRef] [PubMed]

16. Ziegler-Heitbrock, L. Reprint of: Monocyte subsets in man and other species. Cell. Immunol. 2014, 289, 135-139. [CrossRef] [PubMed]

17. Orsini, G.; Legitimo, A.; Failli, A.; Massei, F.; Biver, P.; Consolini, R. Enumeration of human peripheral blood dendritic cells throughout the life. Int. Immunol. 2012, 24, 347-356. [CrossRef] [PubMed]

18. Robinson, S.P.; Patterson, S.; English, N.; Davies, D.; Knight, S.C.; Reid, C.D.L. Human peripheral blood contains two distinct lineages of dendritic cells. Eur. J. Immunol. 1999, 29, 2769-2778. [CrossRef]

19. Förster, R.; Mattis, A.E.; Kremmer, E.; Wolf, E.; Brem, G.; Lipp, M. A putative chemokine receptor, BLR1, directs $\mathrm{B}$ cell migration to defined lymphoid organs and specific anatomic compartments of the spleen. Cell 1996, 87, 1037-1047. [CrossRef]

20. Ansel, K.M.; Ngo, V.N.; Hyman, P.L.; Luther, S.A.; Förster, R.; Sedgwlck, J.D.; Browning, J.L.; Upp, M.; Cyster, J.G. A chemokine-driven positive feedback loop organizes lymphoid follicles. Nature 2000, 406, 309-314. [CrossRef] [PubMed]

21. Fehniger, T.A.; Cooper, M.A.; Nuovo, G.J.; Cella, M.; Facchetti, F.; Colonna, M.; Caligiuri, M.A. CD56bright natural killer cells are present in human lymph nodes and are activated by T cell-derived IL-2: A potential new link between adaptive and innate immunity. Blood 2003, 101, 3052-3057. [CrossRef]

22. Lanier, L.L.; Le, A.M.; Civin, C.I.; Loken, M.R.; Phillips, J.H. The relationship of CD16 (Leu-11) and Leu-19 (NKH-1) antigen expression on human peripheral blood NK cells and cytotoxic T lymphocytes. J. Immunol. 1986, 136, 4480-4486.

23. Poli, A.; Michel, T.; Thérésine, M.; Andrès, E.; Hentges, F.; Zimmer, J. CD56brightnatural killer (NK) cells: An important NK cell subset. Immunology 2009, 126, 458-465. [CrossRef]

24. Lopez-Vergès, S.; Milush, J.M.; Pandey, S.; York, V.A.; Arakawa-Hoyt, J.; Pircher, H.; Norris, P.J.; Nixon, D.F.; Lanier, L.L. CD57 defines a functionally distinct population of mature NK cells in the human CD56dimCD16+NK-cell subset. Blood 2010, 116, 3865-3874. [CrossRef]

25. Mattei, F.; Schiavoni, G.; Belardelli, F.; Tough, D.F. IL-15 Is Expressed by Dendritic Cells in Response to Type I IFN, Double-Stranded RNA, or Lipopolysaccharide and Promotes Dendritic Cell Activation. J. Immunol. 2001, 167, 1179-1187. [CrossRef]

26. Anguille, S.; Van Acker, H.H.; Van Den Bergh, J.; Willemen, Y.; Goossens, H.; Van Tendeloo, V.F.; Smits, E.L.; Berneman, Z.N.; Lion, E. Interleukin-15 dendritic cells harness NK cell cytotoxic effector function in a contactand IL-15-dependent manner. PLoS ONE 2015, 10, e0123340. [CrossRef]

27. Gasteiger, G.; Fan, X.; Dikiy, S.; Lee, S.Y.; Rudensky, A.Y. Tissue residency of innate lymphoid cells in lymphoid and nonlymphoid organs. Science 2015, 350, 981-985. [CrossRef]

28. Ginhoux, F.; Jung, S. Monocytes and macrophages: Developmental pathways and tissue homeostasis. Nat. Rev. Immunol. 2014, 14, 392. [CrossRef]

29. Herbst, B.; Köhler, G.; Mackensen, A.; Veelken, H.; Lindemann, A. GM-CSF promotes differentiation of a precursor cell of monocytes and langerhans-type dendritic cells from CD34+ haemopoietic progenitor cells. Br. J. Haematol. 1998, 101, 231-241. [CrossRef]

30. Kingston, D.; Schmid, M.A.; Onai, N.; Obata-Onai, A.; Baumjohann, D.; Manz, M.G. The concerted action of GM-CSF and Flt3-ligand on in vivo dendritic cell homeostasis. Blood 2009, 114, 835-843. [CrossRef]

31. MacDonald, K.P.A.; Munster, D.J.; Clark, G.J.; Dzionek, A.; Schmitz, J.; Hart, D.N.J. Characterization of human blood dendritic cell subsets. Blood 2002, 100, 4512-4520. [CrossRef] [PubMed]

32. Grouard, G.; Rissoan, M.C.; Filgueira, L.; Durand, I.; Banchereau, J.; Liu, Y.J. The enigmatic plasmacytoid T cells develop into dendritic cells with interleukin (IL)-3 and CD40-ligand. J. Exp. Med. 1997, 185, 1101-1111. [CrossRef] [PubMed] 
33. Cella, M.; Jarrossay, D.; Faccheth, F.; Alebardi, O.; Nakajima, H.; Lanzavecchia, A.; Colonna, M. Plasmacytoid monocytes migrate to inflamed lymph nodes and produce large amounts of type I interferon. Nat. Med. 1999, 5, 919. [CrossRef]

34. Mckenna, H.J.; Stocking, K.L.; Miller, R.E.; Brasel, K.; De Smedt, T.; Maraskovsky, E.; Maliszewski, C.R.; Lynch, D.H.; Smith, J.; Pulendran, B.; et al. Mice lacking flt3 ligand have deficient hematopoiesis affecting hematopoietic progenitor cells, dendritic cells, and natural killer cells. Blood 2000, 95, 3489-3497. [PubMed]

35. Masten, B.J.; Olson, G.K.; Kusewitt, D.F.; Lipscomb, M.F. Flt3 Ligand Preferentially Increases the Number of Functionally Active Myeloid Dendritic Cells in the Lungs of Mice. J. Immunol. 2004, 172, 4077-4083. [CrossRef]

36. Waskow, C.; Liu, K.; Darrasse-Jèze, G.; Guermonprez, P.; Ginhoux, F.; Merad, M.; Shengelia, T.; Yao, K.; Nussenzweig, M. The receptor tyrosine kinase Flt3 is required for dendritic cell development in peripheral lymphoid tissues. Nat. Immunol. 2008, 9, 676-683. [CrossRef] [PubMed]

37. Collin, M.; Mcgovern, N.; Haniffa, M. Human dendritic cell subsets. Immunology 2013, 140, 22-30. [CrossRef] [PubMed]

38. Nie, C.; Sato, K.; Misawa, N.; Kitayama, H.; Fujino, H.; Hiramatsu, H.; Heike, T.; Nakahata, T.; Tanaka, Y.; Ito, M.; et al. Selective infection of CD4+ effector memory T lymphocytes leads to preferential depletion of memory T lymphocytes in R5 HIV-1-infected humanized NOD/SCID/IL-2R rnull mice. Virology 2009, 394, 64-72. [CrossRef]

39. Watanabe, S.; Terashima, K.; Ohta, S.; Horibata, S.; Yajima, M.; Shiozawa, Y.; Zahidunnabi Dewan, M.; Yu, Z.; Ito, M.; Morio, T.; et al. Hematopoietic stem cell-engrafted NOD/SCID/IL2R $\gamma$ nullmice develop human lymphoid systems and induce long-lasting HIV-1 infection with specific humoral immune responses. Blood 2007, 109, 212-218. [CrossRef]

40. Sato, K.; Nie, C.; Misawa, N.; Tanaka, Y.; Ito, M.; Koyanagi, Y. Dynamics of memory and naïve CD8+ T lymphocytes in humanized NOD/SCID/IL-2R $\gamma$ null mice infected with CCR5-tropic HIV-1. Vaccine 2010, 28 (Suppl. 2), B32-B37. [CrossRef]

41. Février, M.; Dorgham, K.; Rebollo, A. CD4+T cell depletion in human immunodeficiency virus (HIV) infection: Role of apoptosis. Viruses 2011, 3, 586-612. [CrossRef] [PubMed]

42. Cummins, N.W.; Badley, A.D. Mechanisms of HIV-associated lymphocyte apoptosis: 2010. Cell Death Dis. 2010, 1, e99. [CrossRef] [PubMed]

43. Wang, L.; Chen, J.J.; Gelman, B.B.; Konig, R.; Cloyd, M.W. A novel mechanism of CD4 lymphocyte depletion involves effects of HIV on resting lymphocytes: Induction of lymph node homing and apoptosis upon secondary signaling through homing receptors. J. Immunol. 1999, 162, 268-276. [PubMed]

44. Chen, J.J.-Y.; Huang, J.C.; Shirtliff, M.; Briscoe, E.; Ali, S.; Cesani, F.; Paar, D.; Cloyd, M.W. CD4 lymphocytes in the blood of HIV + individuals migrate rapidly to lymph nodes and bone marrow: Support for homing theory of CD4 cell depletion. J. Leukoc. Biol. 2002, 72, 271-278. [PubMed]

45. Tedla, N.; Palladinetti, P.; Kelly, M.; Kumar, R.K.; DiGirolamo, N.; Chattophadhay, U.; Cooke, B.; Truskett, P.; Dwyer, J.; Wakefield, D.; et al. Chemokines and T lymphocyte recruitment to lymph nodes in HIV infection. Am. J. Pathol. 1996, 148, 1367. [PubMed]

46. Cagigi, A.; Mowafi, F.; Phuong Dang, L.V.; Tenner-Racz, K.; Atlas, A.; Grutzmeier, S.; Racz, P.; Chiodi, F.; Nilsson, A. Altered expression of the receptor-ligand pair CXCR5/CXCL13 in B cells during chronic HIV-1 infection. Blood 2008, 112, 4401-4410. [CrossRef] [PubMed]

47. Moir, S.; Malaspina, A.; Pickeral, O.K.; Donoghue, E.T.; Vasquez, J.; Miller, N.J.; Krishnan, S.R.; Planta, M.A.; Turney, J.F.; Justement, J.S.; et al. Decreased survival of B cells of HIV-viremic patients mediated by altered expression of receptors of the TNF superfamily. J. Exp. Med. 2004, 200, 587-599. [CrossRef] [PubMed]

48. Ho, J.; Moir, S.; Malaspina, A.; Howell, M.L.; Wang, W.; DiPoto, A.C.; O'Shea, M.A.; Roby, G.A.; Kwan, R.; Mican, J.M.; Chun, T.-W.; et al. Two overrepresented B cell populations in HIV-infected individuals undergo apoptosis by different mechanisms. Proc. Natl. Acad. Sci. USA 2006, 103, 19436-19441. [CrossRef] [PubMed]

49. Perreau, M.; Savoye, A.-L.; De Crignis, E.; Corpataux, J.-M.; Cubas, R.; Haddad, E.K.; De Leval, L.; Graziosi, C.; Pantaleo, G. Follicular helper T cells serve as the major CD4 T cell compartment for HIV-1 infection, replication, and production. J. Exp. Med. 2013, 210, 143-156. [CrossRef] [PubMed] 
50. Pallikkuth, S.; Sharkey, M.; Babic, D.Z.; Gupta, S.; Stone, G.W.; Fischl, M.A.; Stevenson, M.; Pahwa, S. Peripheral T Follicular Helper Cells Are the Major HIV Reservoir within Central Memory CD4 T Cells in Peripheral Blood from Chronically HIV-Infected Individuals on Combination Antiretroviral Therapy. J. Virol. 2016, 90, 2718-2728. [CrossRef] [PubMed]

51. Boswell, K.L.; Paris, R.; Boritz, E.; Ambrozak, D.; Yamamoto, T.; Darko, S.; Wloka, K.; Wheatley, A.; Narpala, S.; McDermott, A.; et al. Loss of Circulating CD4 T Cells with B Cell Helper Function during Chronic HIV Infection. PLoS Pathog. 2014, 10, e1003853. [CrossRef] [PubMed]

52. Muema, D.M.; Macharia, G.N.; Olusola, B.A.; Hassan, A.S.; Fegan, G.W.; Berkley, J.A.; Urban, B.C.; Nduati, E.W. Proportions of circulating follicular helper T cells are reduced and correlate with memory B cells in HIV-infected children. PLoS ONE 2017, 12, e0175570. [CrossRef] [PubMed]

53. Lindqvist, M.; van Lunzen, J.; Soghoian, D.Z.; Kuhl, B.D.; Ranasinghe, S.; Kranias, G.; Flanders, M.D.; Cutler, S.; Yudanin, N.; Muller, M.I.; et al. Expansion of HIV-specific T follicular helper cells in chronic HIV infection. J. Clin. Investig. 2012, 122, 3271-3280. [CrossRef] [PubMed]

54. Perdomo-Celis, F.; Taborda, N.A.; Rugeles, M.T. Circulating CXCR5-expressing CD8+T-Cells are Major Producers of IL-21 and Associate with Limited HIV Replication. J. Acquir. Immune Defic. Syndr. 2018, 78, 473-482. [CrossRef] [PubMed]

55. Petrovas, C.; Ferrando-Martinez, S.; Gerner, M.Y.; Casazza, J.P.; Pegu, A.; Deleage, C.; Cooper, A.; Hataye, J.; Andrews, S.; Ambrozak, D.; et al. H I V Follicular CD8 T cells accumulate in HIV infection and can kill infected cells in vitro via bispecific antibodies. Sci. Transl. Med. 2017, 9, 1-14. [CrossRef]

56. Chen, P.; Su, B.; Zhang, T.; Zhu, X.; Xia, W.; Fu, Y.; Zhao, G.; Xia, H.; Dai, L.; Sun, L.; et al. Perturbations of monocyte subsets and their association with $\mathrm{T}$ helper cell differentiation in acute and chronic HIV-1-infected patients. Front. Immunol. 2017, 8, 272. [CrossRef]

57. Neil, S.; Martin, F.; Ikeda, Y.; Collins, M. Postentry Restriction to Human Immunodeficiency Virus-Based Vector Transduction in Human Monocytes. J. Virol. 2001, 75, 5448-5456. [CrossRef] [PubMed]

58. Arfi, V.; Riviere, L.; Jarrosson-Wuilleme, L.; Goujon, C.; Rigal, D.; Darlix, J.-L.; Cimarelli, A. Characterization of the Early Steps of Infection of Primary Blood Monocytes by Human Immunodeficiency Virus Type 1. J. Virol. 2008, 82, 6557-6565. [CrossRef] [PubMed]

59. Shive, C.L.; Jiang, W.; Anthony, D.D.; Lederman, M.M. Soluble CD14 is a nonspecific marker of monocyte activation. AIDS 2015, 29, 1263-1265. [CrossRef] [PubMed]

60. Sonza, S.; Mutimer, H.P.; Oelrichs, R.; Jardine, D.; Harvey, K.; Dunne, A.; Purcell, D.F.; Birch, C.; Crowe, S.M. Monocytes harbour replication-competent, non-latent HIV-1 in patients on highly active antiretroviral therapy. AIDS 2001, 15, 17-22. [CrossRef] [PubMed]

61. Fontaine, J.; Coutlée, F.; Tremblay, C.; Routy, J.; Poudrier, J.; Roger, M. HIV Infection Affects Blood Myeloid Dendritic Cells after Successful Therapy and despite Nonprogressing Clinical Disease. J. Infect. Dis. 2009, 199, 1007-1018. [CrossRef] [PubMed]

62. Pacanowski, J.; Kahi, S.; Baillet, M.; Lebon, P.; Deveau, C.; Goujard, C.; Meyer, L.; Oksenhendler, E.; Sinet, M.; Hosmalin, A. Reduced blood CD123+(lymphoid) and CD11c+(myeloid) dendritic cell numbers in primary HIV-1 infection. Blood 2001, 98, 3016-3021. [CrossRef] [PubMed]

63. Iannetta, M.; Savinelli, S.; Rossi, R.; Mascia, C.; Marocco, R.; Vita, S.; Zuccalà, P.; Zingaropoli, M.A.; Mengoni, F.; Massetti, A.P.; et al. Myeloid and lymphoid activation markers in AIDS and non-AIDS presenters. Immunobiology 2018, S0171-298, 30214-30216. [CrossRef] [PubMed]

64. Barron, M.A.; Blyveis, N.; Palmer, B.E.; MaWhinney, S.; Wilson, C.C. Influence of plasma viremia on defects in number and immunophenotype of blood dendritic cell subsets in human immunodeficiency virus 1-infected individuals. J. Infect. Dis. 2003, 18, 26-37. [CrossRef] [PubMed]

65. Pinzon-Charry, A.; Ho, C.S.K.; Laherty, R.; Maxwell, T.; Walker, D.; Gardiner, R.A.; O'Connor, L.; Pyke, C.; Schmidt, C.; Furnival, C.; et al. A Population of HLA-DR+ Immature Cells Accumulates in the Blood Dendritic Cell Compartment of Patients with Different Types of Cancer. Neoplasia 2005, 7, 1112-1122. [CrossRef]

66. Donaghy, H.; Gazzard, B.; Gotch, F.; Patterson, S. Dysfunction and infection of freshly isolated blood myeloid and plasmacytoid dendritic cells in patients infected with HIV-1. Blood 2003, 101, 4505-4511. [CrossRef] [PubMed] 
67. Tarazona, R.; Casado, J.G.; Delarosa, O.; Torre-Cisneros, J.; Villanueva, J.L.; Sanchez, B.; Galiani, M.D.; Gonzalez, R.; Solana, R.; Pena, J. Selective depletion of CD56dimNK cell subsets and maintenance of CD56brightNK cells in treatment-naive HIV-1-seropositive individuals. J. Clin. Immunol. 2002, 22, 176-183. [CrossRef] [PubMed]

68. Hong, H.S.; Ahmad, F.; Eberhard, J.M.; Bhatnagar, N.; Bollmann, B.A.; Keudel, P.; Ballmaier, M.; Zielinska-Skowronek, M.; Schmidt, R.E.; Meyer-Olson, D. Loss of CCR7 Expression on CD56bright NK Cells Is Associated with a CD56dimCD16+ NK Cell-Like Phenotype and Correlates with HIV Viral Load. PLOS ONE 2012, 7, e44820. [CrossRef] article distributed under the terms and conditions of the Creative Commons Attribution (CC BY) license (http://creativecommons.org/licenses/by/4.0/). 